Microscopical examination of these flatly worn surfaces showed that they are due to artificial abrasion and not to natural wear. The canine is a young tooth with incomplete root, so the fact that it has been worn right down to the pulp cavity, as in an aged individual, is only explicable by artificial abrasion.

Re-determination of the fluorine content of all the specimens, using an improved technique, has shown that whereas the brain-case contains the same amount of fluorine as some local Upper Pleistocene fossils, the jawbone and the canine contain no more than modern specimens. The organic content of all the specimens has also been determined. The jawbone and the canine contain as much nitrogen as fresh bones and teeth; but the brain-case contains only the small quantity expected in Upper Pleistocene fossils.

Finally, evidence has been found which indicates that the jawbone was artificially stained by iron salts and potassium dichromate prior to its being 'discovered' by the excavators. Some who were at first sceptical about the association of the human brain-case with an ape-like jaw and canine tooth became convinced that it was a genuine association, and not a fortuitous one, when it was announced that remains of another individual had been found at a second site. Tests applied to the two pieces of skull bone alleged to be from the second site show that whereas one piece is fossilized and probably belongs to the skull from the first site, the other piece is comparatively modern and has been artificially stained in an attempt to match it in colour. A molar tooth reputed to be from this second site shows signs of artificial abrasion and almost certainly came from the original 'Piltdown mandible'.

The tests and other investigations reported above were carried out jointly in the Departments of Geology and Mineralogy of the British Museum, in the Department of Anatomy and the Clarendon Laboratory, University of Oxford, and in the Department of the Government Chemist, London.

These investigations serve to confirm the doubts expressed by certain men of science during the controversy which raged for some years after the original discovery in 1912. For example, exactly forty years ago, Prof. D. Waterston, then professor of anatomy in King's College, London, after superimposing tracings of the radiograms of the Piltdown mandible and that of a chimpanzee, wrote (Nature, $92,319 ; 1913)$ : "The similarity of the specimens brought out in this way is very striking, for the outlines are practically identical. . . . The cranial fragments of the Piltdown skull, on the other hand, are in practically all their details essentially human. If that be so it seems to me to be as inconsequent to refer the mandible and the cranium to the same individual as it would be to articulate a chimpanzee foot with the bones of an essentially human thigh and leg". A similar view was expressed by Mr. G. Miller, jun., in the United States after systematic comparison of the casts of the Piltdown fossils with the corresponding bones of men and apes.

\title{
OBITUARY
}

\section{Dr. O. F. Hudson}

Dr. Hudson, whose death occurred on October 8, had taken an early and prominent part in the development and application of the techniques of metallography and thermal analysis, and had made valuable contributions to progress, both as a teacher and by his researches, at a time when there were but few workers in this field.

Born in 1878, Oswald Freeman Hudson was educated at Alleyn's School, Dulwich, and entered the Royal College of Science in 1897, taking the associateship in chemistry in 1900. After a period at the Royal School of Mines, under Prof. RobertsAusten, he went to the Mint as one of his research assistants. It was there that he had what was at that time the almost unique opportunity of acquiring experience in metallurgical research, under the guidance of the late Prof. W. H. Merrett. Work was then in progress for the sixth of the series of reports which Roberts-Austen had made to the Alloys Research Committee of the Institution of Mechanical Engineers during the preceding decade.

In 1902 the late Prof. Thomas Turner was engaged in planning and equipping the Metallurgical Department in the new buildings of the University of Birmingham, and Hudson went there as his lecturer in metallurgy. During the next fourteen years he devoted himself wholeheartedly both to teaching and to research. His work, chiefly on the copperzinc alloys, and partly in collaboration with the late Dr. G. D. Bengough, appeared in the Journal of the Society of Chemical Industry. With the advent, in 1908, of the Institute of Metals, of which he was an original member, he became a regular contributor to the Proceedings and discussions of that body. He took a leading part in forming the London
Local Section, and became the first chairman in 1921. The breadth of his metallurgical interests while at Birmingham is shown by the publication of a concise but admirable text-book on "Iron and Steel" in 1913, to which his friend Bengough contributed a section on corrosion.

In 1916, Hudson returned to London to collaborate with Bengough in the urgent work of the Corrosion Research Committee, sponsored by the Institute of Metals and under the chairmanship of the late Sir Harold Carpenter at the Royal School of Mines.

Two years later he was appointed metallurgist to the Admiralty Engineering Laboratory at West Drayton, Middlesex. There he remained until 1924, the nature of his work being confidential. Returning to Birmingham, he then assisted Dr. R. S. Hutton (now emeritus professor at Cambridge) in setting up the British Non-Ferrous Metals Research Association, afterwards transferred to the present buildings in Euston Street, London. As research superintendent he served this body for the next fifteen years, and was retained as consultant until 1944. During the Second World War he resumed his association with Prof. Hutton as a part-time lecturer at Cambridge and he also responded to a similar call for assistance at the Royal School of Mines.

Thus, over a period of more than forty years, Dr. Hudson had taken a prominent part in many new metallurgical developments and had witnessed. the striking advances that have been made. His self-effacing modesty and natural gift for friendly collaboration had endeared him to a wide circle of fellow-metallurgists, who, either as former students or as colleagues, had profited by his guidance and help in their work.
S. W. Sмттн 